\section{REFERENCES}

1. Plouin PF, Perdu J, La Batide-Alanore A, Boutouyrie P, Gimenez-Roqueplo AP, Jeunemaitre X. Fibromuscular dysplasia. Orphanet J Rare Dis 2007;2:28.

2. Slovut DP, Olin JW. Fibromuscular dysplasia. N Engl J Med 2004;350: 1862-1871.

3. Dayes LA, Gardiner N. The neurological implications of fibromuscular dysplasia. Mt Sinai J Med 2005;72:418-420.

4. Stahlfeld KR, Means JR, Didomenico P. Carotid artery fibromuscular dysplasia. Am J Surg 2007;193:71-72.

5. Touzé E, Oppenheim C, Trystram D, et al. Fibromuscular dysplasia of cervical and intracranial arteries. Int J Stroke 2010;5:296-305.
DISPLASIA FIBROMUSCULAR COMO CAUSA RARA DE ACIDENTE VASCULAR ISOUÊMICO EM JOVEM

Neurorehabilitation Unit, IRCCS Centro Neurolesi "Bonino-Pulejo", Messina, Italy: ${ }^{1} \mathrm{MD} ;{ }^{2} \mathrm{PhD}$.

Correspondence: Giuseppe Gervasi - IRCCS Centro Neurolesi "Bonino-Pulejo" - S.S.113 via Palermo, Cda Casazza - 98124 Messina, Italy. E-mail: giuseppe. gervasi@centroneurolesi.it

Received 10 December 2010. Received in final form 15 December 2010. Accepted 22 December 2010

\title{
SCA2 presenting as an ataxia-parkinsonism-motor neuron disease syndrome
}

\author{
Pedro Braga-Neto, José Luiz Pedroso, André Carvalho Felício, Agessandro Abrahão, \\ Lívia Almeida Dutra, Marcio Luiz Escorcio Bezerra, Orlando Graziani Povoas Barsottini
}

The procedures followed were in accordance with the ethical standards of the responsible committee on human experimentation (institutional and national). All subjects were provided with the approved informed consent.

Spinocerebellar ataxia type 2 (SCA2) is characterized by progressive cerebellar ataxia, slow saccadic eye movements and peripheral neuropathy. Atypical SCA2 phenotypes with prominent dementia, an amyotrophic lateral sclerosis-like presentation, and levodopa-responsive parkinsonism are also encountered ${ }^{1}$. The definite diagnosis of SCA2 is based on clinical symptoms and molecular genetic testing to detect an abnormal CAG trinucleotide repeat expansion of the ATXN2 gene on chromosome $12 \mathrm{q}^{1}$. The protein synthesized by ATXN2 is known as ataxin-2 that is involved in RNA metabolism and translation regulation ${ }^{1}$. Herein we report an unusual case of SCA2 presenting as an ataxia-parkinsonism-motor neuron disease (MND) syndrome.

\section{CASE}

A 46-year-old Brazilian man of Italian ancestry, presented for consultation because of progressive gait instability and muscle cramps that started 18 months before. He also developed rapidly progressive muscle weakness few months before his first appointment. His family history revealed affected individuals (ataxia) within first and second generations. On neurological examination, there were mild dysarthria, slow saccades, mild limb and gait ataxia, parkinsonism, brisk reflexes and bilateral Babinski sign. He also presented muscle weakness in upper limbs, diffuse fasciculations and atrophy involving upper limbs, chest and face. Genetic testing confirmed the diagnosis

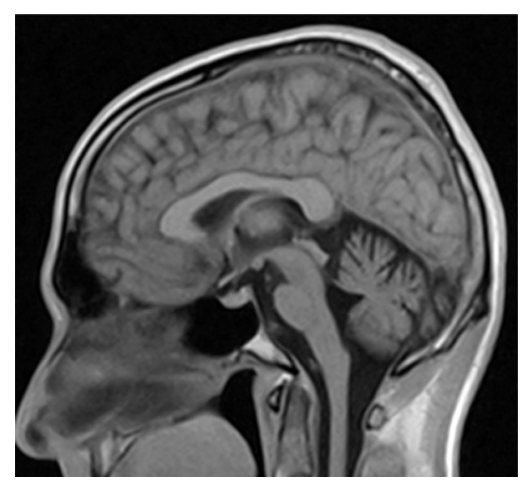

Figure. Sagittal $\mathrm{T}_{1}$ brain MRI disclosing cerebellar and brainstem atrophy. This imaging finding is frequently seen in SCA2.

of SCA2 with 40 CAG repeats. Brain magnetic resonance imaging (MRI) disclosed cerebellar and brainstem atrophy (Figure). Electroneuromyography showed denervation activity at rest, with fasciculation, fibrillation and positive sharp wave potentials in the bulbar, cervical, thoracic and lumbosacral regions. Nerve conduction studies showed normal sensory and motor nerve conduction velocities and reduced amplitudes of the motor potentials. We introduced riluzole $50 \mathrm{mg}$ b.i.d. as treatment for amyotrophic lateral sclerosis (ALS).

\section{DISCUSSION}

Few previous studies have described the association of SCA2 with MND. Infante et $\mathrm{al}^{2}{ }^{2}$ reported a case of a 61 years-old woman with SCA2 diagnosis who developed a levodopa-responsive parkinsonism after 6 months of the ataxia-onset of symptoms, but later on disease course 
presented MND syndrome ${ }^{2}$. Recently, Nanetti et al. ${ }^{3}$ described another 66 year-old woman with SCA2 affected with progressive weakness and fasciculation ${ }^{3}$. Our patient was younger than the previous reports and presented MND disease shortly after SCA2 diagnosis.

In 2006, the $43-\mathrm{kDa}$ TAR DNA binding protein (TDP-43) was identified as the major disease protein in ALS and frontotemporal lobar degeneration with ubiquinated inclusions ${ }^{4}$. Recently, Elden et al. ${ }^{5}$ pointed out to ATXN2 gene as a relatively common suitability gene to ALS. They demonstrated that ATXN2 is a potent modifier of TDP-43 toxicity in animal and cellular models. In addition, 6 patients with ALS were evaluated and disclosed different ATXN2 localization in spinal cord ${ }^{5}$.

This report highlights that unusual phenotypes such as an ataxia-parkinsonism-motor neuron disease syndrome may be found in SCA 2 individuals. This raises several questions such as whether or not patients investigating MND with or without known family members with cerebellar ataxia should be routinely screened for ATXN2. Future studies with larger series are welcome to address these questions.

\section{REFERENCES}

1. Lastres-Becker I, Rüb U, Auburger G. Spinocerebellar ataxia 2 (SCA2) Cerebellum 2008;7:115-124.

2. Infante J, Berciano J, Volpini V, et al. Spinocerebellar ataxia type 2 with levodopa-responsive parkinsonism culminating in motor neuron disease. Mov Disord 2004;19:848-852.

3. Nanetti L, Fancellu R, Tomasello C, Gellera C, Pareyson D, Mariotti C. Rare association of motor neuron disease and spinocerebellar ataxia type 2 (SCA2): a new case and review of the literature. J Neurol 2009;256: 1926-1928.

4. Neumann M, Sampathu DM, Kwong LK, et al. Ubiquitinated TDP-43 in frontotemporal lobar degeneration and amyotrophic lateral sclerosis. Science 2006;314:130-133.

5. Elden AC, Kim HJ, Hart MP, et al. Ataxin-2 intermediate-length polyglutamine expansions are associated with increased risk for ALS. Nature 2010:466:1069-1075

\section{APRESENTAÇ̃̃O CLÍNICA DE SCA2 COMO UMA SÍNDROME ATAXIA-} PARKINSONISMO-DOENÇA DO NEURÔNIO MOTOR

Department of Neurology and Neurosurgery, Division of General Neurology and Ataxias, Universidade Federal de São Paulo, São Paulo SP, Brazil.

Correspondence: Pedro Braga-Neto - Rua Pedro de Toledo 650 - 04030-002 São Paulo SP - Brasil. E-mail: pbraganeto@hotmail.com

Received 9 December 2010. Accepted 2 February 2011.

\title{
Facial grimacing as a clue for the diagnosis of GM1 type 3 gangliosidosis
}

\author{
Ricardo Oliveira Horta Maciel', José Luiz Pedroso², Orlando G.P. Barsottini ${ }^{3}$
}

GM1 Gangliosidosis is an autosomal recessive lysosomal storage disease caused by the deficiency of betagalactosidase. Only few cases have been reported in the literature, owing to the rarity of the condition but also possibly due to its underrecognition in clinical practice ${ }^{1,2}$. Reports of GM1 gangliosidosis type 3 patients and recent literature review shows that oromandibular dystonia producing the aprearance of grimacing is a common feature of this disorder ${ }^{2}$. Herein we describe a patient in wich proeminent facial grimacing served as a clue to the diagnosis of GM1 gangliosidosis type 3. The patients legal guardian gave consent to publish this case.

A 20 year-old female patient had a normal development until the age of 3 years, when the parents noted speech impairment wich worsened to the point of ininteligibility in the following years. With 5 years cognitive deterioration in other areas was noted and the child was never able to attend school. Gait abnormality also developed and by the age 11 she was unable to walk or stand. On examination the patient had short stature and moderate thoracic kyphosis. Tongue and orofacial dystonia where present, giving the appearance of grimacing (Figure). There was also dystonia of the feet, dystonic posturing of the hands while at rest and increased tonus in the legs. No bradykynesia or dysmetria were noted. Strenght was normal with brisk reflexes and flexor plantar responses. There was no corneal clouding. Slitlamp examination and fundoscopy were normal. Bone radiographies revealed kyphoscoliosis and femoral dysplasia. Routine brain MRI showed T2 hypointensity of the globus pallidus and hydrocephalus caused by a incidental ependimoma of the fourth ventricule. Routine blood and CSF examination were unremarkable. An abdominal ultrasound showed no abnormalities. Beta-glicuronidase, galacto-6-sulphatase and hexosaminidase A (testing for mucopolysaccharidosis IV, VII and Tay-Sachs disease, respectively) were normal. Leukocyte beta-galactosidade activity measured in serum was $5.7 \mathrm{nmol} / \mathrm{h} /$ 